\title{
Critical Damage Analysis of WC-Co Tip of Conical Pick due to Coal Excavation in Mines
}

\author{
Saurabh Dewangan, ${ }^{1}$ Somnath Chattopadhyaya, ${ }^{1}$ and Sergej Hloch ${ }^{2}$ \\ ${ }^{1}$ Department of Mechanical Engineering, Indian School of Mines, Dhanbad 826004, India \\ ${ }^{2}$ Faculty of Manufacturing Technologies, Technical University of Košice with a Seat in Prešov, 08001 Presov, Slovakia
}

Correspondence should be addressed to Saurabh Dewangan; saurabh22490@gmail.com

Received 21 August 2014; Revised 7 December 2014; Accepted 10 December 2014

Academic Editor: Guocheng Lv

Copyright (C) 2015 Saurabh Dewangan et al. This is an open access article distributed under the Creative Commons Attribution License, which permits unrestricted use, distribution, and reproduction in any medium, provided the original work is properly cited.

WC-Co based tools are widely used in the field of coal and rock excavation because of their unique combination of strength, hardness, and resistance to abrasive wear. Conical pick is one of the coal cutting tools. The tip of the pick is made of WC-Co material. As coal and rock are heterogeneous elements, they pose various constraints during excavation. As a result the tools wear out during the process. Other parameters like cutting techniques, tool orientation, and environmental conditions also affect the tool significantly. The wearing phenomenon greatly reduces the service life of the tools and thereby cuts down the production rate. To prevent such wearing process, it is important to investigate the different wear mechanisms in WC-Co. Simultaneously, there has to be an ongoing endeavour for the development of better quality WC-Co. This paper focuses on different wear mechanisms in a conical pick which has been used in a continuous miner machine for coal cutting. The worn out surface has been observed by using FE-SEM (field emission scanning electron microscopy) and EDS (energy dispersive X-ray spectroscopy). The mechanisms, namely, coal/rock intermixing, cracking and crushing of WC grains, and adhesion of rock particles, have been predominantly investigated in this study. A little indication of corrosive decay in the WC grain has also been reported. The EDS has detected material concentration in a selected area or point of the worn-out surface. The spectrograph confirms the presence of coal/rock materials. Elements such as W, C, Ca, K, O, and Co have been mainly found in different concentrations at different positions.

\section{Introduction}

Conical pick is an essential tool in the field of coal/rock excavation. The abrasive cone tip is made of cemented carbide material and is inserted in a steel body. Cemented carbide is a binary composition of WC and Co. It is extensively used in excavating machines, such as continuous miner, roadheader, and shearer. Picture of a continuous miner is shown in Figure 1(a). Cemented carbide has the ideal combination of hardness and toughness. Tungsten carbide possesses strength and hardness whereas the cobalt is responsible for toughness $[1,2]$. The grain size of carbide affects wear-resistance property of the cemented carbide. The coarse-grained carbides usually have a lower abrasive wearresistance than that of a fine or medium grain size [3-8]. By increasing the granule size of carbides, the fracture toughness increases [9]. Factors such as rock types, abrasiveness, drilling temperature, rock penetration, and corrosive environment around tool can result in various wear mechanisms [10, 11]. Different drilling patterns can also be the cause of different failure mechanisms. If percussion drilling is carried out, then it causes fatigue impact wearing as the main failure mechanism. Again, when the rotary/crushing is the drilling pattern, it is abrasion and crack that become the primary characteristics of failure mechanism [12-14]. Beste et al. (2006) have studied mainly two deterioration mechanisms in rock drill buttons. They are binder phase degradation and rock intermixing [15]. Larsen-Basse (1973) has concluded in a review that rock drill bit wear can be explained by the following mechanisms: surface impact spalling, surface impact fatigue spalling, thermal fatigue, and abrasion [16]. However, the generated heat during drilling process greatly affects the sustainability of tools. Fish et al. (1957) have found that hard rock drilling leads to a process of tool material softening due to high button temperature. Moreover, the necessary high load generates high frictional heat [17]. The 


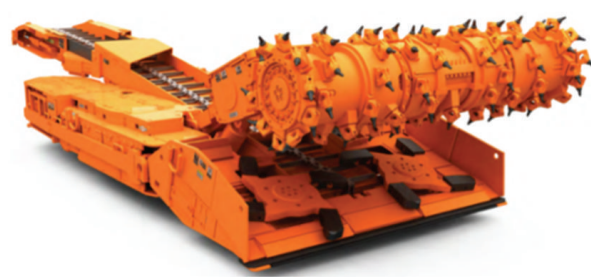

(a)
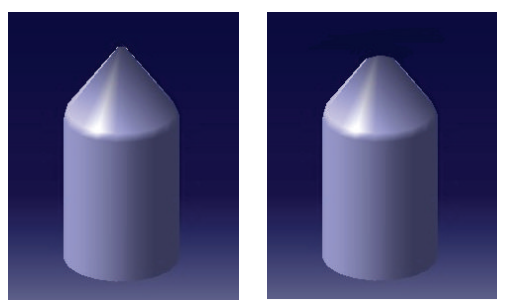

(b)

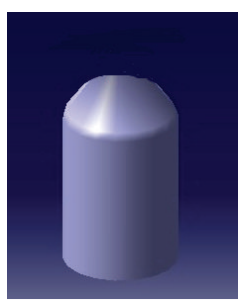

FIGURE 1: (a) Continuous miner machine (courtesy: joy global) [27]; (b) gradual wear of WC-Co tip.

actual surface temperature of the drill button is difficult to measure. However, the average temperature has been reported to be between $300^{\circ} \mathrm{C}$ and $400^{\circ} \mathrm{C}$ [10]. Also, oxidation of Co takes place near the crack tips at higher temperature which results in brittle-ductile transitions [18]. The thermal fatigue crack propagation in WC-Co has been studied by Lagerquist [19] and the rate-controlling factor has been found to be the width of Co layers between the adjacent WC grains. Many researchers have studied wear mechanisms of CC tool with SEM (scanning electron microscopy) and high resolution field emission gun SEM analysis. They have found different types of damage in the cemented carbide buttons, namely, microspalling, abrasion wear, cracks, WC grain pullout, extrusion of binder metal, and reptile skin [11, $13,14,16,20-23]$. In an experiment, Olovsjö et al. (2013) have concluded that the controlling parameters of the wearing process in $\mathrm{CC}$ are plastic deformation and cracking and crushing of individual WC grains. Cobalt depletion and rock material penetration may also affect the drill button life to a great extent [24]. Gupta et al. (2012) have carried out SEM analysis of worn out diamond cutting tool and unused tool to compare the microstructure after rock cutting. The new tool has displayed properly bonded diamond particles in nickel matrix. However, channels or grooves can be seen in the worn-out part due to combined effect of excessive loading and bit rotation. It has also been noticed that the matrix is plastically deformed due to the high temperature produced during core drilling [25]. After investigating various wear mechanisms in CC drill bits, researchers believe that there have to be further studies in this area $[24,26]$.

The present paper studies wear mechanisms in the WCCo tip of a worn-out conical pick, which has been used in a coal cutting operation by a continuous miner machine. A sketch of gradual wearing of the WC-Co tip is given in Figure 1(b). It is important to organize adequate samples of worn-out tools for critical investigation. The field emission scanning electron microscopy (FESEM) and energy dispersive X-ray spectrography (EDS) have been used to observe the severity of damage and deterioration. FESEM has more advantages over SEM in terms of better quality images with higher magnification. EDS helps to find the exact amount of material concentration in the selected point/area. Hence, the detection of rock/coal materials in the selected part of WCCo structure can be made properly.

\section{Experimental Work}

The experimental work primarily consisted of organizing a worn-out sample to make critical observation. It required a small-sized sample of the work piece for getting correct results in SEM analysis. If the tip is inserted deeply into the tool body, it becomes difficult to cut the hard WC-Co material properly. Therefore, the tip was cut by electric discharge machining (EDM). The microscopic analysis was done with the FE-SEM Supra 55 (Carl Zeiss, Germany). The worn-out conical pick and the sample, which were observed through SEM, are shown in Figures 2(a), 2(b), and 2(c).

The cracks and crushed parts in the tip surface could be seen by naked eyes as in the referred figure but the microstructural damage inside could not be seen. By using SEM and EDS, different types of wear mechanisms were found.

\section{Observation}

The SEM is capable of detecting the microstructural damage. Simultaneously, the factors causing the damage in a particular area can be detected through EDS. For taking SEM images of different parts, some adjustments had to be made, regarding the magnification, accelerating voltage or electron high tension (EHT), working distance (WD) between the sample surface and the lower portion of the lens, and so forth. These are shown in each of the SEM images. Different types of wear mechanisms could be observed in the surface of the worn-out sample. Cracking and crushing of WC grains, interruption of coal and rock particles, and adhesion of rock materials into the surface were found to be the main wear mechanisms.

Hard rocks are always present in between coals in a mine. These undesirable rock materials are the main cause behind tool damage. With the drum of the continuous miner machine rotating at $54 \mathrm{rpm}$, the tool is hit by coal and rock during cutting. The sudden high impact leads to cracking and crushing of the WC grains, rendering the tool absolutely useless. The cracks in the WC grains are shown in Figure 3. During this process, some sharp edges of rocks penetrate the cracks, thereby crushing the WC grains. In some cases, small fragments of crushed WC grains come out, making a hole in the original structure (Figure 4). Sometimes these holes are filled with coal/rock material.

$\mathrm{Coal} /$ rock interruption in between the WC-Co structures is a common wear mechanism in any coal cutting equipment. 


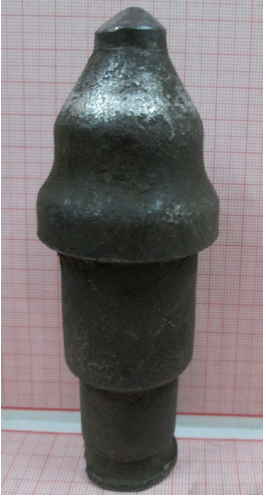

(a)

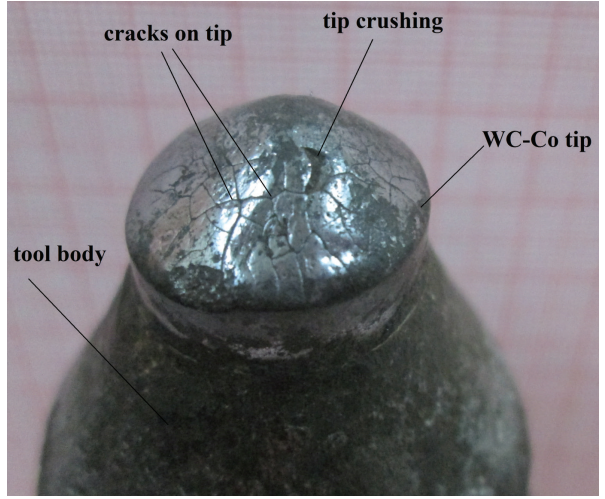

(b)

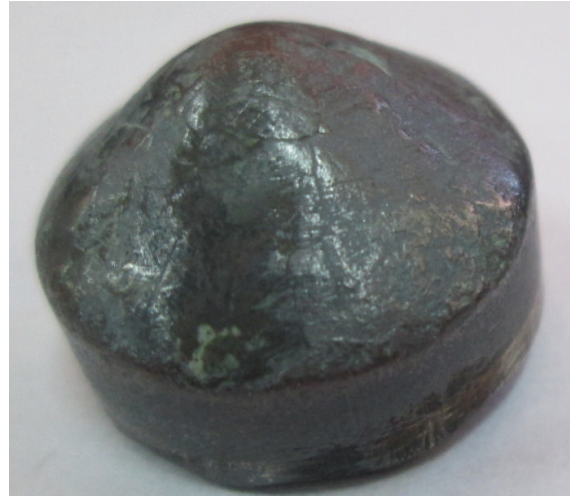

(c)

FIGURE 2: (a) Worn-out conical pick; (b) crushing and cracking of WC-Co tip; (c) sample to be tested on SEM.

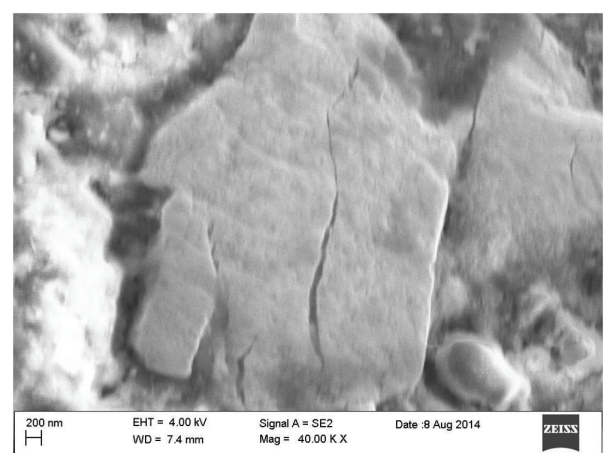

FIGURE 3: Crack on WC grain.

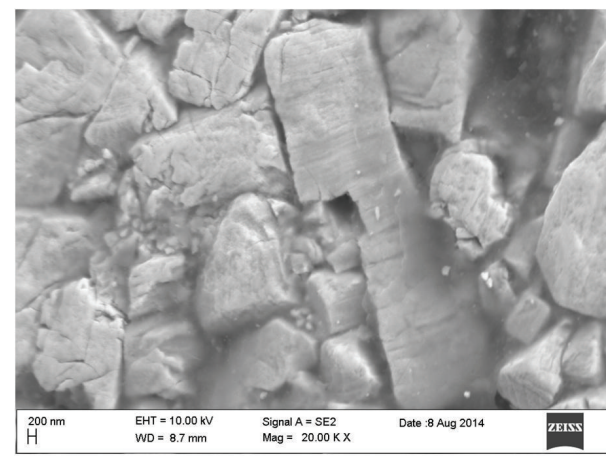

FIGURE 4: Crushing of WC grains; hole due to penetration of sharp edge of hard rock.

The Co binder phase is ductile in nature and due to the massive impact, the rock/coal particles enter into the binder phase and get mixed with them. This results in the degradation of the Co phase. As a result, it can no longer bind the WC grains properly. Rock/coal intermixing can be assumed to be the main factor which triggers other types of deterioration in the tool. The presence of coal/rock has been confirmed by the EDS analysis. The spectra plotted by EDS are capable

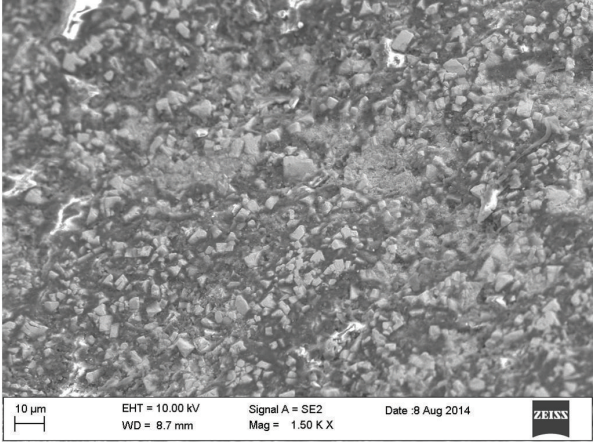

FIGURE 5: Coal/rock particle interruption (black portion) in between the WC grains.

of showing the percentage concentration of mixed rock/coal materials. The coal and rock interrupted zone (black part) in the surface of the tip is shown in Figure 5. Coal intermixing at another part of the sample is shown in Figure 6. For capturing this image, the magnification and accelerating voltage had to be adjusted at $2.00 \mathrm{Kx}$ and $10.00 \mathrm{kV}$, respectively. For the purpose, an area marked spectrum 1 was selected for observation of the concentration of coal and rock materials through EDS. The data obtained through EDS reveals that mainly W, C, and $\mathrm{O}$ are in excess and their weights (\%) are 39.53, 35.89, and 20.81 , respectively. $\mathrm{Ca}(0.77 \%)$ and $\mathrm{Co}(3.00 \%)$ are also present in small amount. Here $\mathrm{C}$ represents the coal particles and $\mathrm{Ca}$ and $\mathrm{O}$ are the sign of rock parts. As the tool was used in a coal mine, mainly coal interruption was observed.

A comparative analysis of EDS spectra at three different zones of the crushed WC surface was done (Figures $7(\mathrm{a})$, $7(b)$, and $7(c))$. All the three figures are the same but the points/areas selected for taking EDS were different. Spectra 1,2 , and 3 have been marked on the solid WC grain, binder material (dark part), and crushed WC grains, respectively. The pertaining EDS images are given in Figures 8(a), 8(b), and $8(\mathrm{c})$. Also, the weight percentage and atomic percentage of the elements of the corresponding images have been noted 


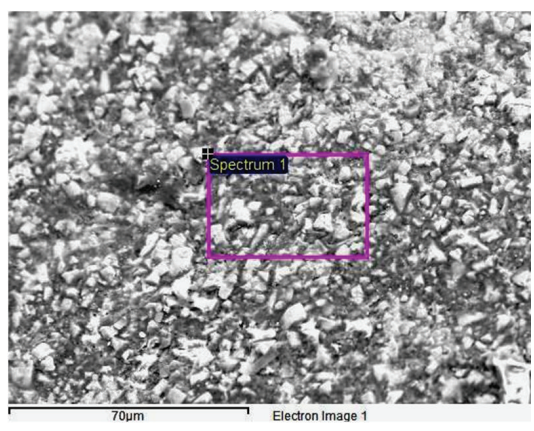

(a)

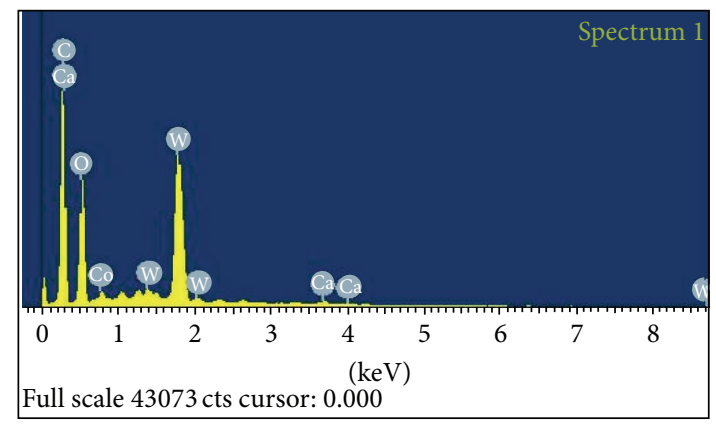

(b)

FIGURE 6: (a) Coal/rock intermixed zone (dark coloured); (b) EDS spectra of selected area showing the presence of coal and rock material.

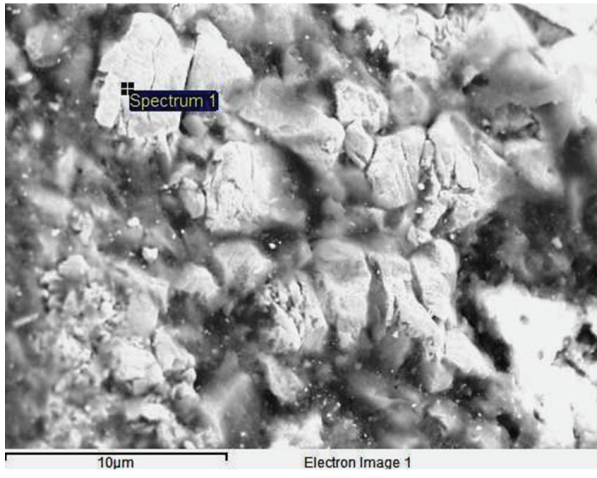

(a)

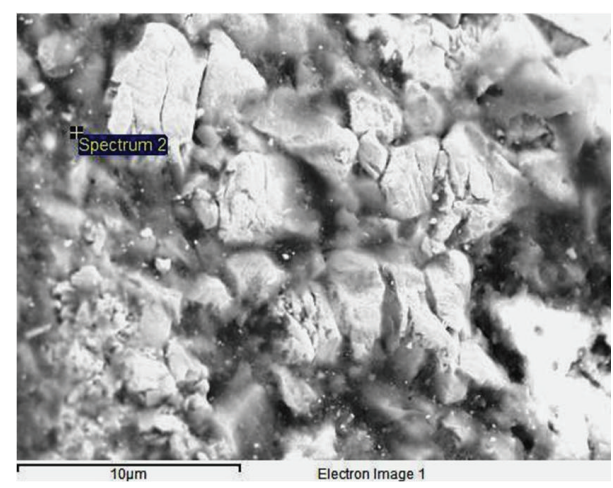

(b)

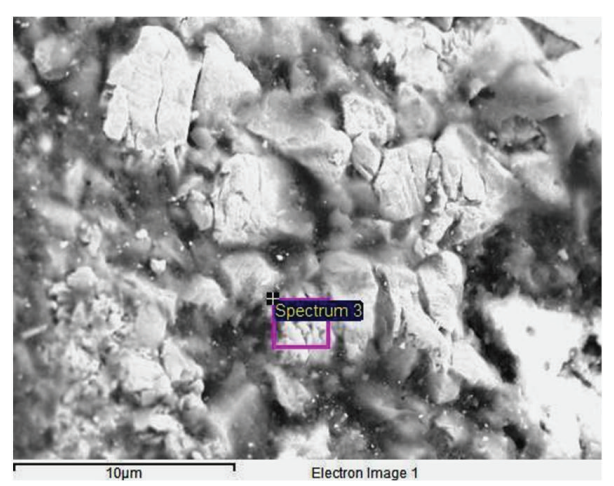

(c)

FIgURE 7: Crushed part of tool tip; different points/area selected for EDS analysis.

down. This process verifies the presence of coal and rock in the damaged tip surface. The damaged part shows very little amount of Co indicating that it has been degraded by coal/rock materials.

The homogeneous $\alpha$-tungsten carbide contains tungsten and carbon in an exact stoichiometric ratio of 49.5$50.5 \mathrm{~mol} \%$ carbon [28]. Pure tungsten powder is mixed with pure carbon (lamp black) in the ratio of $94 \%$ and $6 \%$ by weight at a high heat of about $1400-2000^{\circ} \mathrm{C}[28,29]$. Hence, it is natural to find a concentration of $\mathrm{C}$ in the $\mathrm{WC}$ grain. On the basis of the spectrum 1 (a point on solid WC grain) it can be concluded that the $\mathrm{W}$ and $\mathrm{C}$ are the main constituent of the WC grain, although a small amount of $\mathrm{O}$ is also present due to the deteriorated condition of the surface. Spectrum 2 (a point selected on binder (black) part) shows a comparatively high amount of carbon and oxygen content and also a little amount of $\mathrm{Mg}, \mathrm{Ca}$, and $\mathrm{Al}$, indicating intermixing of coal and rock material with the binder phase. The area of spectrum 3 in the crushed WC grains also shows the presence of penetrated coal and rock materials (see Figure 8).

The adhesion of coal/rock particle into the surface of cemented carbide is another wear mechanism. The observed rock material is shown in Figure 9 (magnification $=14.00 \mathrm{Kx}$ ). This phenomenon enhances the rock interruption in between 


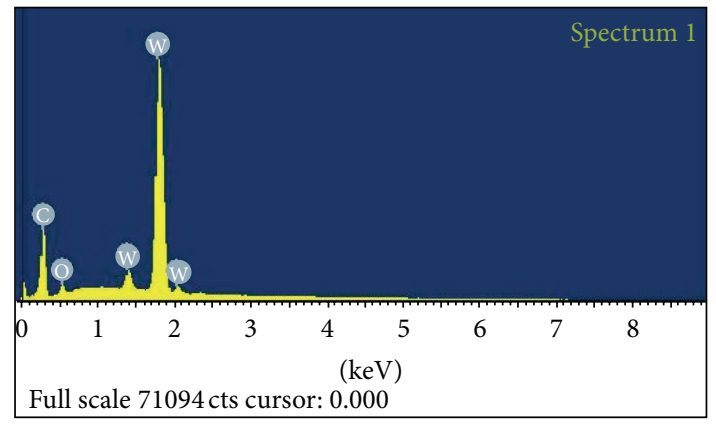

\begin{tabular}{lrr}
\hline Element & Weight\% & Atomic\% \\
\hline C K & 19.10 & 74.04 \\
O K & 2.06 & 5.99 \\
W M & 78.84 & 19.97 \\
\hline Total & & 100.00 \\
\hline
\end{tabular}

(a)

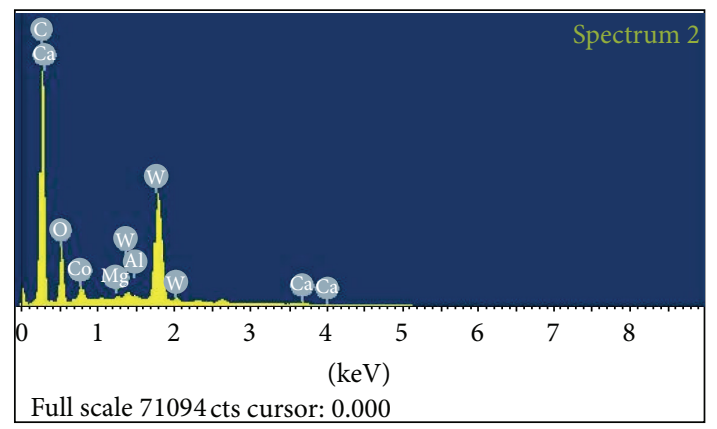

\begin{tabular}{lcc}
\hline Element & Weight\% & Atomic\% \\
\hline C K & 45.37 & 77.59 \\
O K & 12.25 & 15.73 \\
Mg K & 0.29 & 0.24 \\
Al K & 0.29 & 0.22 \\
Ca K & 0.54 & 0.28 \\
Co L & 5.62 & 1.96 \\
W M & 35.65 & 3.98 \\
\hline Total & \multicolumn{2}{c}{100.00} \\
\hline
\end{tabular}

(b)

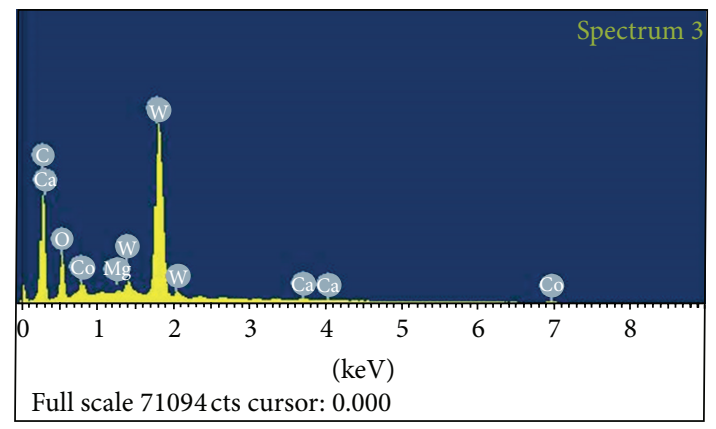

\begin{tabular}{lcc}
\hline Element & Weight\% & Atomic\% \\
\hline C K & 26.14 & 68.01 \\
O K & 9.40 & 18.36 \\
Mg K & 0.33 & 0.43 \\
Ca K & 0.60 & 0.47 \\
Co L & 5.38 & 2.85 \\
W M & 58.14 & 9.88 \\
\hline Total & & 100.00 \\
\hline
\end{tabular}

(c)

FIGURE 8: EDS pertaining to area selected in Figure 7; (a) EDS of a point selected in Figure 7(a) on WC grain; (b) EDS of a point selected in Figure 7(b) on dark part; (c) EDS of an area selected in Figure 7(c) on crushed WC grain.

the binder contents. The rock and coal materials adhere to the surface due to the high impact caused by moving roller of continuous miner machine at the time of coal cutting. As the number of rotations increases, the rock particle begins to enter into the WC-Co bond by replacing the Co binder phase. The rectangular area (spectrum 1) was selected for observing the EDS result (Figure 9). Excess carbon indicates presence of the coal materials. Rock materials like $\mathrm{N}$ and $\mathrm{O}$ were also significantly visible.

Beste and Jacobson (2008) explained the chemical and oxidative degradation of the WC grains by SEM images in which the oxides were shown in the form of white circular spots. They also pointed out decay of the WC grains due to corrosive environment [26]. Similar corrosive decay to an extent was reported in the present experiment as well. However, the oxide layers or spots are not present in this experimented sample. The corrosive degradation has been shown inside the white oval (Figure 10).

\section{Conclusion}

For a long time, the wearing mechanisms of CC have been under study. In order to enhance the quality of CC, it is important to understand the wearing process of CC under different working conditions. In the present study, an attempt has been made to understand the deterioration mechanisms in a worn out conical pick. The pick was being used in continuous miner machine for coal mining. The tool sample was 


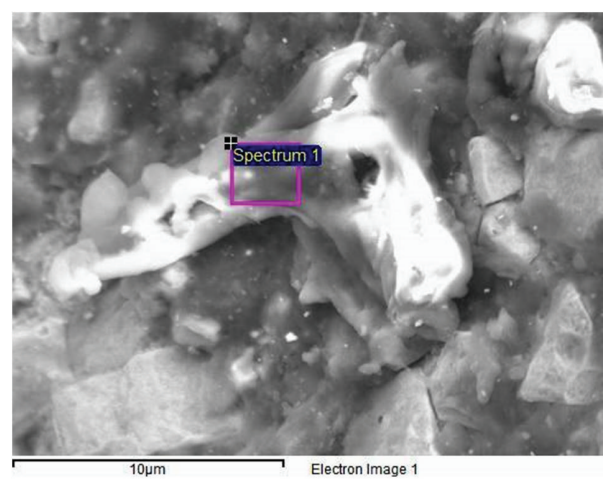

(a)

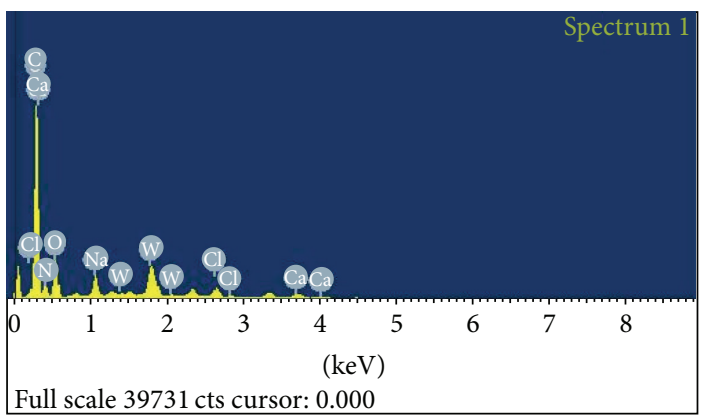

\begin{tabular}{lcc}
\hline Element & Weight\% & Atomic\% \\
\hline $\mathrm{C} \mathrm{K}$ & 50.45 & 65.19 \\
$\mathrm{~N} \mathrm{~K}$ & 14.69 & 16.28 \\
$\mathrm{O} \mathrm{K}$ & 14.25 & 13.82 \\
$\mathrm{Na} \mathrm{K}$ & 2.52 & 1.70 \\
$\mathrm{Cl} \mathrm{K}$ & 2.66 & 1.17 \\
$\mathrm{Ca} \mathrm{K}$ & 1.80 & 0.70 \\
$\mathrm{~W} \mathrm{M}$ & 13.62 & 1.15 \\
\hline Total & \multicolumn{2}{c}{100.00} \\
\hline
\end{tabular}

(b)

FIGURE 9: Adhering of rock particle; EDS spectra showing the concentration of elements.

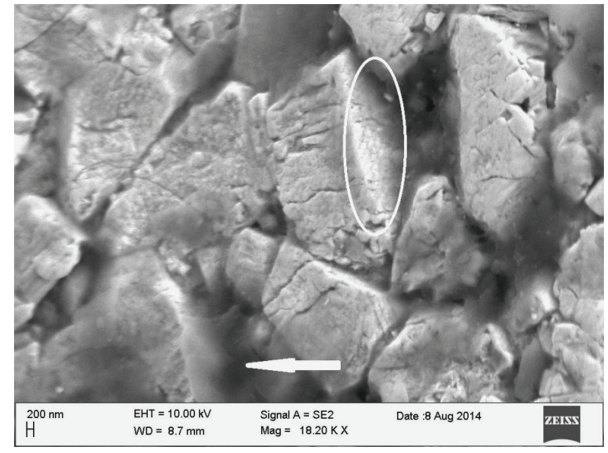

FIGURE 10: Corrosive degradation of WC grain (white oval); white arrow shows the coal/rock intermixed binder material.

carefully investigated through FE-SEM and EDS for a thorough understanding of the wearing mechanism. Although cracks and crushed parts in the surface were clearly visible by naked eyes, the severity of damage could be assessed only by using SEM. Also, the material (element) concentrations in the damaged part were detected by EDS. Different types of wear mechanisms, namely, coal/rock interruption, cracking and crushing of WC grains, adhesion of rock particles, and a small indication of corrosive decay in the WC grains, were reported. Predominantly, WC grain cracking and crushing could be detected. The conclusion that could be made at the end of the study was that coal/rock materials penetrate the cracks of the coal cutting tools to enter inside the base material and degrade it. A small percentage of intermixed rock material in the present investigation indicated that the quality of coal is good in this particular mine under study and has very little amount of rock present in between the coals.

\section{Conflict of Interests}

The authors declare that there is no conflict of interests regarding the publication of this paper.

\section{References}

[1] A. Mukhopadhyay and B. Basu, "Recent developments on WCbased bulk composites," Journal of Materials Science, vol. 46, no. 3, pp. 571-589, 2011.

[2] G. S. Upadhyaya, "Materials science of cemented carbides-an overview," Materials and Design, vol. 22, no. 6, pp. 483-489, 2001.

[3] K. Bonny, P. De Baets, Y. Perez, J. Vleugels, and B. Lauwers, "Friction and wear characteristics of WC-Co cemented carbides in dry reciprocating sliding contact," Wear, vol. 268, no. 11-12, pp. 1504-1517, 2010.

[4] J. Pirso, S. Letunovitš, and M. Viljus, "Friction and wear behaviour of cemented carbides," Wear, vol. 257, no. 3-4, pp. 257-265, 2004.

[5] T. Kagnaya, C. Boher, L. Lambert, M. Lazard, and T. Cutard, "Wear mechanisms of WC-Co cutting tools from high-speed tribological tests," Wear, vol. 267, no. 5-8, pp. 890-897, 2009.

[6] J. Deng, J. Zhou, H. Zhang, and P. Yan, "Wear mechanisms of cemented carbide tools in dry cutting of precipitation hardening 
semi-austenitic stainless steels," Wear, vol. 270, no. 7-8, pp. 520527, 2011.

[7] G. List, M. Nouari, D. Géhin et al., "Wear behaviour of cemented carbide tools in dry machining of aluminium alloy," Wear, vol. 259, no. 7-12, pp. 1177-1189, 2005.

[8] J. Y. Sheikh-Ahmad and J. A. Bailey, "The wear characteristics of some cemented tungsten carbides in machining particleboard," Wear, vol. 225-229, no. I, pp. 256-266, 1999.

[9] X. Deng, B. R. Patterson, K. K. Chawla et al., "Mechanical properties of a hybrid cemented carbide composite," International Journal of Refractory Metals and Hard Materials, vol. 19, no. 46, pp. 547-552, 2001.

[10] U. Beste, T. Hartzell, H. Engqvist, and N. Axén, "Surface damage on cemented carbide rock-drill buttons," Wear, vol. 249, no. 3-4, pp. 324-329, 2001.

[11] U. Beste and S. Jacobson, "Micro scale hardness distribution of rock types related to rock drill wear," Wear, vol. 254, no. 11, pp. 1147-1154, 2003.

[12] L. C. Duan, X. Y. Liu, B. S. Mao, K. H. Yang, and F. L. Tang, "Research on diamond-enhanced tungsten carbide composite button bits," Journal of Materials Processing Technology, vol. 129, no. 1-3, pp. 395-398, 2002.

[13] J. Larsen-Basse, "Binder extrusion in sliding wear of WC-Co alloys," Wear, vol. 105, no. 3, pp. 247-256, 1985.

[14] K. J. Swick, G. W. Stachowiak, and A. W. Batchelor, "Mechanism of wear of rotary-percussive drilling bits and the effect of rock type on wear," Tribology International, vol. 25, no. 1, pp. 83-88, 1992.

[15] U. Beste, E. Coronel, and S. Jacobson, "Wear induced material modifications of cemented carbide rock drill buttons," International Journal of Refractory Metals and Hard Materials, vol. 24, no. 1-2, pp. 168-176, 2006.

[16] J. Larsen-Basse, "Wear of hard-metals in rock drilling: a survey of the literature," Powder Metallurgy, vol. 16, no. 31, pp. 1-32, 1973.

[17] B. G. Fish, G. A. Guppy, and J. T. Ruden, "Abrasive wear effects in rotary rock drilling," Transactions of the Institutions of Mining and Metallurgy, vol. 63, pp. 357-383, 1959.

[18] P. Kindermann, P. Schlund, H.-G. Sockel et al., "High-temperature fatigue of cemented carbides under cyclic loads," International Journal of Refractory Metals and Hard Materials, vol. 17, no. 1, pp. 55-68, 1999.

[19] M. Lagerquist, "A study of the thermal fatigue crack propagation in WC-Co cemented carbide," Powder Metallurgy, vol. 18, no. 35, pp. 71-88, 1975.

[20] U. Beste and S. Jacobson, "Friction between a cemented carbide rock drill button and different rock types," Wear, vol. 253, no. 11-12, pp. 1219-1221, 2002.

[21] K. G. Stjernberg, U. Fischer, and N. I. Hugoson, "Wear mechanisms due to different rock drilling conditions," Powder Metallurgy, vol. 18, no. 35, pp. 89-106, 1975.

[22] J. Larsen-Basse, C. M. Perrott, and P. M. Robinson, "Abrasive wear of tungsten carbide-cobalt composites. I. Rotary drilling tests," Materials Science and Engineering, vol. 13, no. 2, pp. 8391, 1974.

[23] J. Larsen-Basse, "Effect of composition, microstructure, and service conditions on the wear of cemented carbides," Journal of Metals, vol. 35, no. 11, pp. 35-42, 1983.

[24] S. Olovsjö, R. Johanson, F. Falsafi, U. Bexell, and M. Olsson, "Surface failure and wear of cemented carbide rock drill buttons-the importance of sample preparation and optimized microscopy settings," Wear, vol. 302, no. 1-2, pp. 1546-1554, 2013.

[25] A. Gupta, S. Chattopadhyaya, and S. Hloch, "Critical investigation of wear behaviour of WC drill bit buttons," Rock Mechanics and Rock Engineering, vol. 46, no. 1, pp. 169-177, 2013.

[26] U. Beste and S. Jacobson, "A new view of the deterioration and wear of WC/Co cemented carbide rock drill buttons," Wear, vol. 264, no. 11-12, pp. 1129-1141, 2008.

[27] 14CM Series Continuous Miner Product Review, http://www .joyglobal.com/.

[28] H. Tulhoff, "Carbides. Metal like carbides of industrial importance," in Ullmann's Encyclopedia of Industrial Chemistry, Wiley-VCH, Weinheim, Germany, 2000.

[29] R. K. Rajput, A Textbook of Manufacturing Technology: Manufacturing Process, Firewall Media, 2007. 

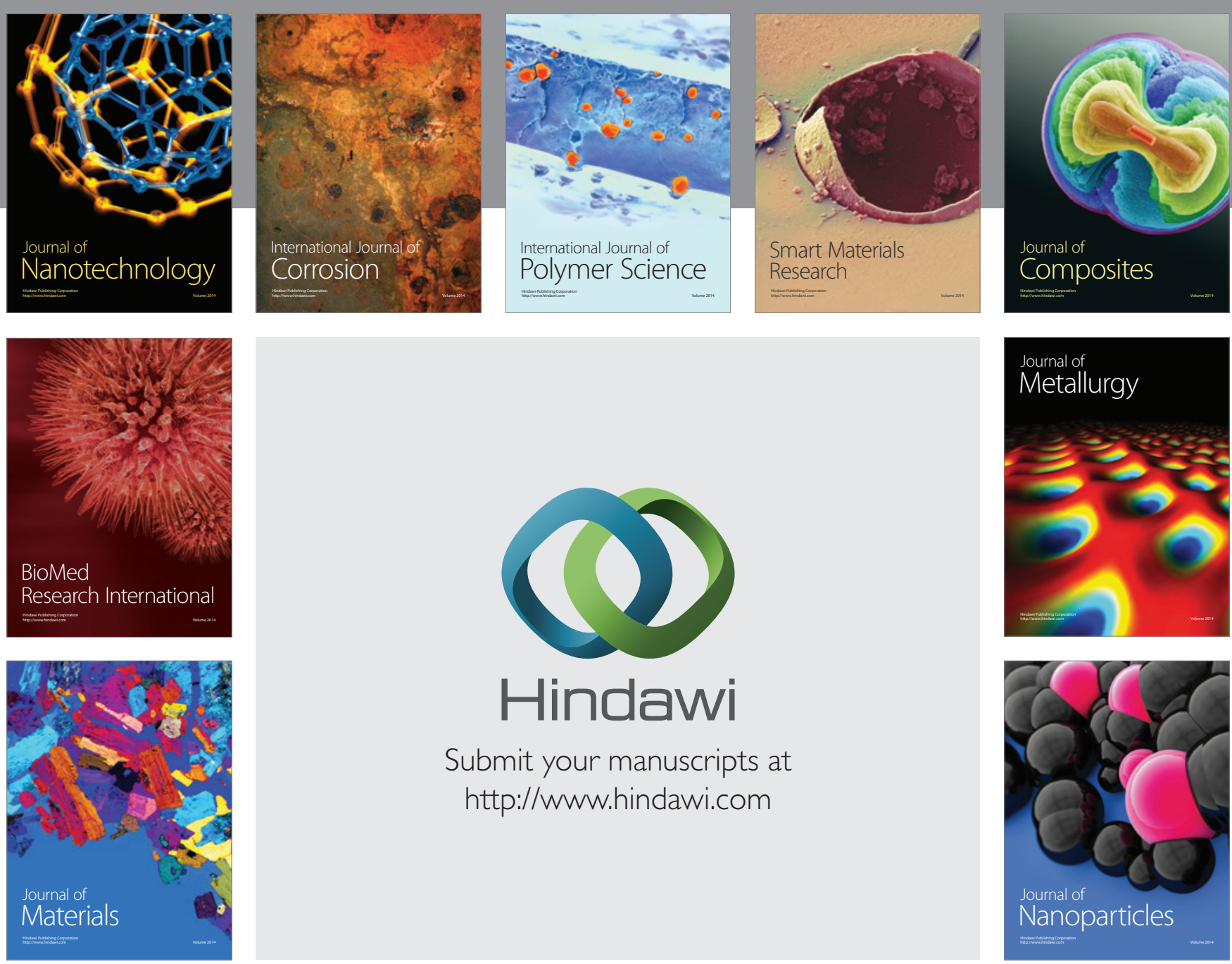

Submit your manuscripts at http://www.hindawi.com
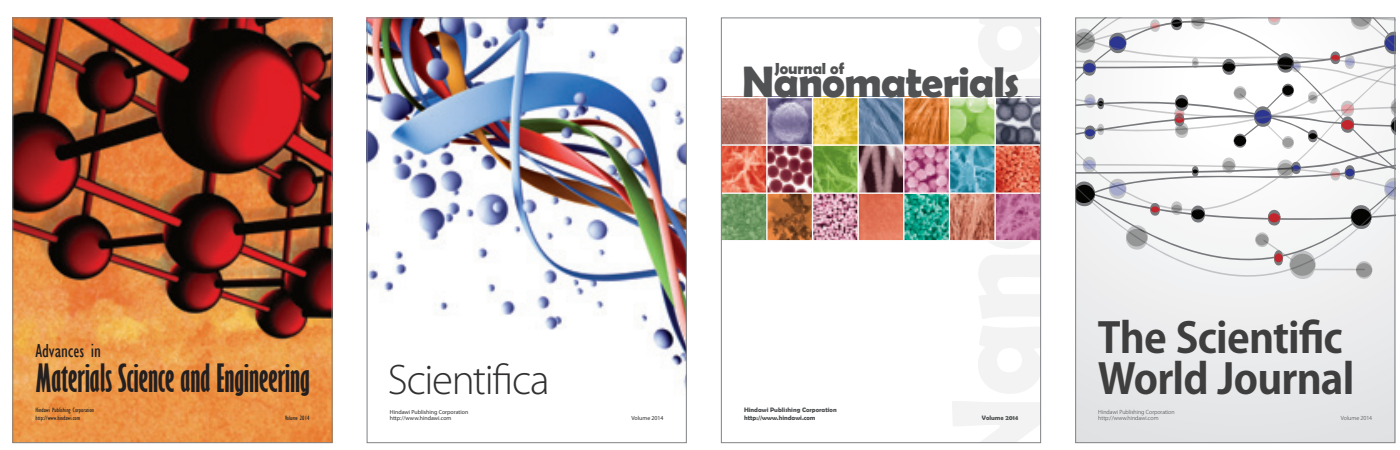

\section{The Scientific World Journal}
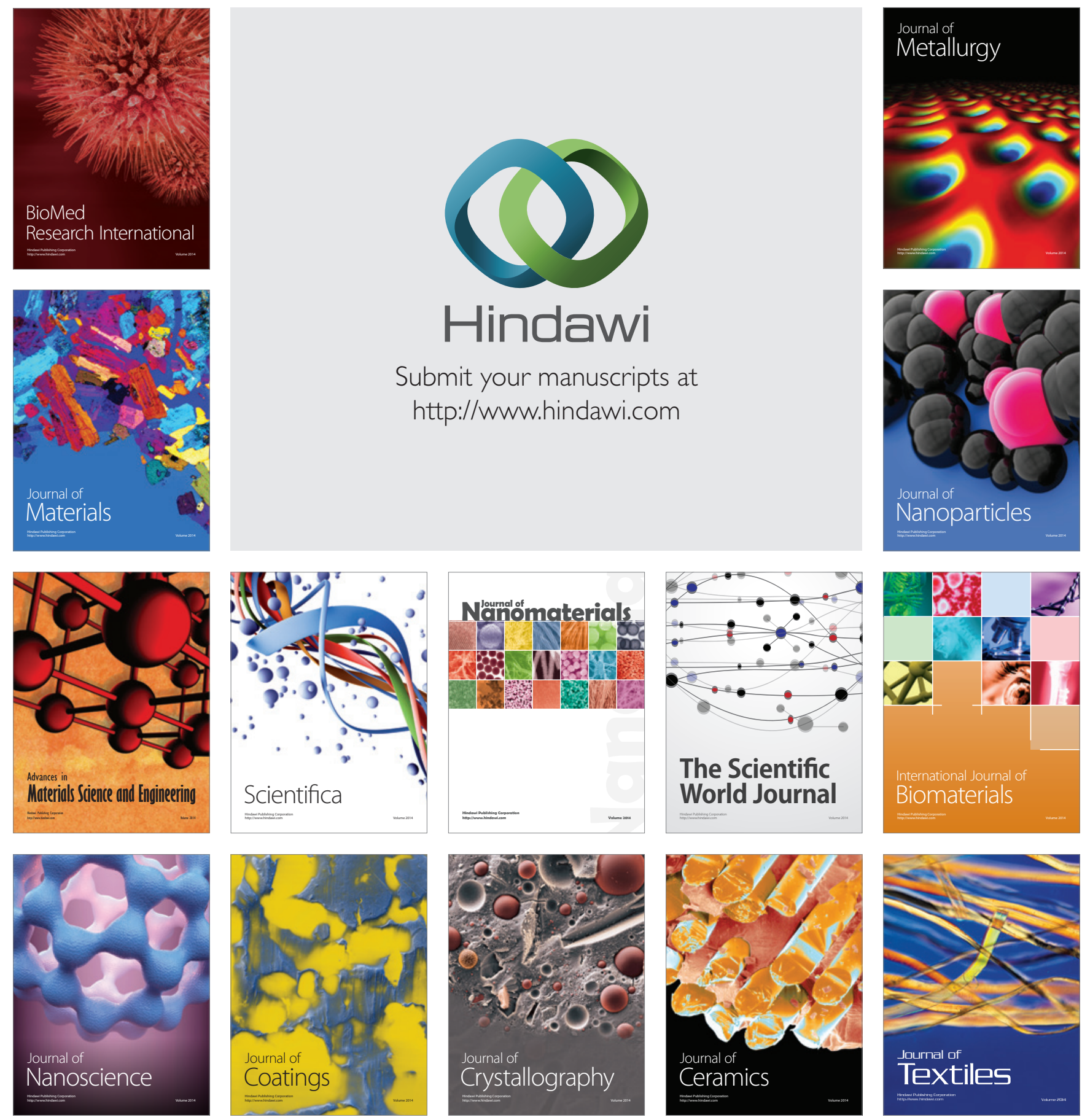